\title{
Providing emotional stability through relaxation training
}

M. Janbozorgi, ${ }^{1}$ A. Zahirodin, ${ }^{1}$ N. Norri, ${ }^{2}$ R. Ghafarsamar ${ }^{3}$ and J. Shams ${ }^{1}$

$$
\begin{aligned}
& \text { توفير الاستقر ار العاطفي من خلال التدريب على الاستـرخاء }
\end{aligned}
$$

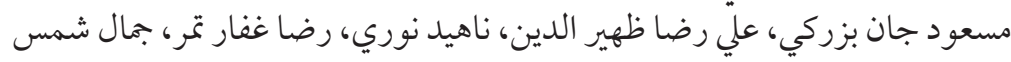

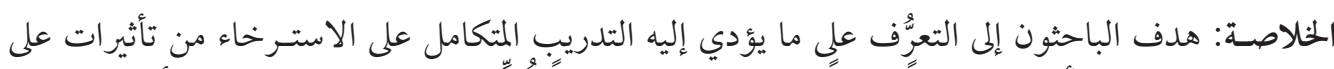

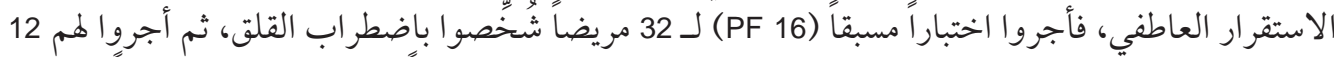

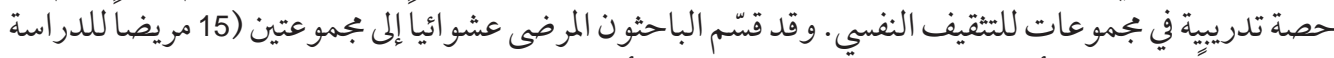

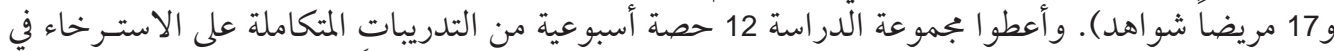

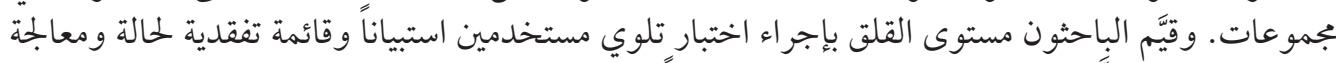

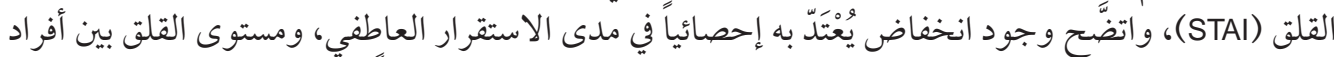

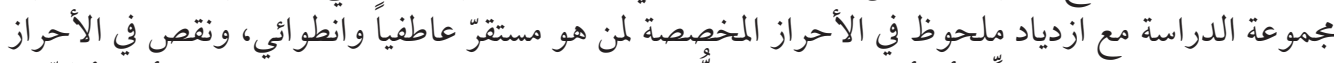

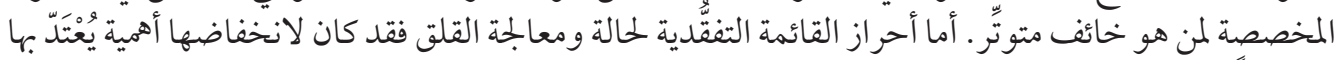

$$
\begin{aligned}
& \text { إحصائياً في بجموعة الدراسة. }
\end{aligned}
$$

ABSTRACT To determine the effects of integrative relaxation training (IRT) on emotional stability, we exposed 32 patients diagnosed with anxiety disorder to a pre-test (16PF) and to 12 sessions of group psychoeducation training. Patients were randomly assigned to 2 groups (study 17 and control 15 patients). The study group received 12 weekly group sessions of IRT. Level of anxiety was evaluated in a post-test using a questionnaire and the State-Trait Anxiety Inventory (STAI). Emotional stability and level of anxiety were significantly reduced in the study group: there was a marked increase in scores for emotionally $s$ and venturesome and a decrease in scores for apprehensive and tense. The STAI score was statistically significantly lower in the study group.

\section{Apporter une stabilité émotionnelle grâce à la relaxation}

RÉSUMÉ Afin de déterminer les effets de la relaxation profonde sur la stabilité émotionnelle, nous avons soumis 32 patients atteints de troubles anxieux à un test préliminaire (16 PF) et à 12 séances de psychoéducation de groupe. Ces patients ont été répartis de façon aléatoire dans deux groupes (17 dans le groupe d'étude et 15 dans le groupe témoin). Le groupe d'étude a suivi 12 séances hebdomadaires collectives de relaxation profonde. Leur niveau d'anxiété a ensuite été évalué à l'aide d'un questionnaire et de l'échelle STAI (State-Trait Anxiety Inventory, ou échelle d'anxiété état-trait). La stabilité émotionnelle et le niveau d'anxiété étaient significativement réduits dans le groupe d'étude : on a observé une nette augmentation des scores pour les traits de personnalité émotionnellement stable et téméraire et une diminution pour inquiet et tendu. Le score STAI était significativement moins élevé du point de vue statistique dans le groupe d'étude.

\footnotetext{
${ }^{1}$ Department of Psychiatry and Behavioural Science Research, Medical Science Centre, Shahid Beheshti University of Medical Science, Tehran, Islamic Republic of Iran (Correspondence to M. Janbozorgi: janbozorgi@sbmu.ac.ir).

${ }^{2}$ Talieh Counselling Centre, Tehran, Islamic Republic of Iran.

${ }^{3}$ Department of English, Tarbiat Modares University, Tehran, Islamic Republic of Iran.

Received 03/10/06; accepted: 11/12/06
}

المجلة الصحية لشرق المتوسط، منظمة الصحة العالمية، المجلد الخنامس عشر، العدد ب، 9 +. 


\section{Introduction}

Emotional stability is a concept which has always been considered a factor of mental health in psychological evaluations. Previous research has demonstrated that daily levels of stress increase with daily fluctuations in mood and as stress increases, mood tends to become more negative [1]. Emotional instability and neuroticism are dimensions of stress and anxiety disorders [2-4], and many aspects of mental health are related to these conditions.

Emotional instability is one of the essential factors affecting anxiety, and the assumption is that if psychological interventions are able to influence this factor, stress and anxiety will be reduced and psychological organization of the patient will be more integrative. Progressive relaxation training (PRT) (adapted from Jacobson method, including only muscle relaxation) is considered one of the most efficient interventions in this regard [5-8].

Various studies have provided evidence for the effects of relaxation techniques on anxiety control and its dependant areas [9-16]. Janbozorgi studied the effects of PRT on some anxiety-related factors of personality and found that relaxation training was able to decrease anxiety [17]. The only factor unchanged was that related to emotional stability (factor C). Cattell noted: "The essence of factor $\mathrm{C}$ appears to be an inability to control one's emotions and impulses, especially by finding for them some satisfactory realistic expression. Looked at from the opposite or positive pole, it sharpens and gives scientific substance to the psychoanalytic concept of 'ego strength', which it (factor C) has come to be called" [18].

In another study Janbozorgi applied a multimodal therapy and found a significant effect on one of the anxiety factors, while state and trait of anxiety were significantly decreased [19]. When this approach was integrated with religious orientation and accompanied with religious exercises, all anxiety factors were significantly changed. Therefore, integration of cultural factors and adopting culturally modified methods of treatment can have positive effects on training and its outcomes.

The idea of an integrated approach to patient care that connects mind, body and spirit is not new [20]. Current approaches have combined cognitive behaviour treatment with relaxation techniques such as breathing exercises and guided imagery rather than combining it with medication. This new combination seems as effective in reducing anxiety as medication, while empowering the client at the same time $[21,22]$. It has also been shown that meditation can be an effective addition to the therapeutic process when used alone or in combination with other approaches (e.g. relaxation) [23]. Thus, combining meditation and spiritual practices with relaxation expands the treatment options. Such approches may bring about healing which is usually seen as restoring a condition of wholeness or harmony [24].

In this study we aimed to explore the effects of progressive relaxation training combined with lifestyle modification and spiritual training and determine their integrated effects on the anxiety factors of personality and emotional stability.

\section{Methods}

\section{Participants and study design}

This study was carried out from March 2005 to October 2005. Patients with a principal DSM-IV (generalized anxiety disorder) diagnosis referred to a counselling and psychotherapy centre (Talieh Counselling 
Centre, a private organization) in Tehran by general practitioners and mental health professionals from both government and private organizations as well as self-referrals were considered for the study. There were a total of 64 referrals to the centre during the study period. We decided to include only those aged $19-35$ years because the majority of the referrals were in this age range. Four people were outside the age limit and were excluded and 6 refused to take part in the study, leaving 54 eligible participants who signed the consent form.

The Structured Clinical Interview was used as the basis for DSM-IV (SCID-IV) diagnosis. Whenever $\geq 1$ diagnosis was identified, clinical interview was used to determine the primary reason for the visit and the degree of interference in functioning, as recommended in DSM-IV [25]. In 19 individuals a principal diagnosis other than generalized anxiety disorder was indicated, so they were excluded from the study. Individuals were also excluded from the study if they were undergoing concurrent psychological treatment for anxiety disorder (2), had a current diagnosis of schizophrenia (1), an intellectual disability (1), or an organic mental disorder (1).

In all, 35 participants completed posttreatment measures; they were divided randomly into 2 groups: 15 (originally 18 , but 3 did not attend the follow-up) were assigned to the study group and 17 to the control group. The psychological variables were measured in the same way for all patients at the first session. We chose a pre-test/post-test design for this study. The experimental procedures to be used were explained to the participants in detail and they were asked about any prior experiences with relaxation training and if they had any motives for learning integrative relaxation training (IRT).

\section{Measures}

The following measures were implemented pre- and post-treatment (control group participants completed the measures at intake and then post-test.)

- We used the Farsi version of the 16PF questionnaire, which was provided by Dadsetan and Delkhamosh, who standardized it for the Iranian population [26] to measure 16 personality factors. It is a 187 -item self-report measure that assesses 16 primary factors. By factor analysis, these can be reduced to $5 \mathrm{sec}-$ ondary factors: extroversion, anxiety, toughness, independence and self-control. We focused only on anxiety factors, especially factor $\mathrm{C}$ (ego strength) in this research. Reported reliability for the $16 \mathrm{PF}$ by test-retest is 0.80 short-term and 0.52 long-term [27].

- State-Trait Anxiety Inventory (STAI) (Iranian form) was used in the post-test. The STAI comprises separate self-report psychometric scales for measuring 2 distinct but related anxiety concepts [28]. The internal consistency of the STAI is relatively high as measured by alpha coefficiencies $(0.90$ or higher for normative samples) [29,30]. The STAI was also standardized for the Iranian situation [31].

Data analysis was conducted using $t$-tests for independent samples to compare mean differences between study and control groups.

\section{Interventions}

The IRT programme is a structured programme attended by participants in groups of $10-15$ persons. Participants were also given a weekly task. The interventions applied during the treatment period included 12-weeks of IRT: a combination of progressive relaxation training adapted from 
Jacobson's programme (cited in Berenstein et al. [32]), a lifestyle relaxation programme (including: organization of sleep time and limitation of daily sleep; healthy eating and drinking; exercise; increase in and development of awareness and consciousness; training in decision-making processes; leisure time management; and guidance for self-dialogue $[33,34])$ and spiritual exercises (religious meditation, prayer and mention or remembrance of God in daily activities).

Each session lasted for about 1.5-2 hours and was divided into 4 sections: review of homework, relaxation training, discussion of lifestyle and spiritual dimensions. Our integrative relaxation timetable for the 12 weeks is presented in Table 1.

The control group completed the questionnaires but did not take part in the interventions.

\section{Statistical analysis}

Statistical significance was analysed using the Student $t$-test. $P$-value $<0.05$ was considered statistically significant.

\section{Results}

The mean age of the participants was 24.64 (standard deviation 3.77 ) years; $35 \%$ were married and $87.5 \%$ were women.

Table 2 shows the comparison of the means and standard deviations of the effects of interventions on each of the 16 personality factors. The mean differences were statistically significant for 4 factors of the $16 \mathrm{PF}(P$ $<0.05$ ). For the study group participants: for factor $\mathrm{H}$ the mean change was 4.78 , for factor $\mathrm{O}$ it was -4.72 , for factor Q4 it was -6.56 and for factor $\mathrm{C} 4.12$ which indicates that they had improved emotional stability, while in the control group this score did not change significantly (Table 2).

To determine whether the interventions could affect the emotional stability and anxiety factors of the personality, we used the Student $t$-test to check for differences between pre- and post-tests. Four factors (C, $\mathrm{H}, \mathrm{O}$ and Q4) of the 16PF scale showed a significant change (Table 3), indicating that participants in study group gained significant stability in their emotions and reduced their anxiety.

The means of variation in factor $\mathrm{H}$ in pre-test and post-test show a significant difference $(t=-2.93, P<0.05)$ (Table 3$)$. The increase of this score of the subjects of the study group shows that social skills could promote stability of our subjects.

The mean score for factor $\mathrm{O}$, however, decreased significantly for the study group compared to the control group $(t=3.03$, $P<0.005)$ (Table 3). The mean score of factor Q4 also decreased significantly in the study group $(t=3.22, P<0.003)$. This kind of change means that our study group participants became significantly more relaxed compared to the subjects of the control group.

After administration of the STAI, StateTrait Anxiety in the study group was statistically significantly lower than in the control group (Table 4).

At the end of the treatment, participants in the study group also reported a reduction in sense of insecurity, amnesia and irritability.

\section{Discussion}

Our results agree with our preliminary assumption that IRT is able to manage emotional stability and anxiety. The anxiety factors of personality, especially those concerning emotional stability, and State-Trait Anxiety were significantly changed after the treatment. These findings are consistent with some previous studies that have shown that relaxation training may reduce anxiety in patients [7-12,17]. Although previous re-

المجلة الصحية لشرق المتوسط، منظمة الصحة العالمية، المجلد الخامس عشر، العلد ب، 9 + •r 


\begin{tabular}{|c|c|c|}
\hline Session & Topic & Description \\
\hline 1 & Rationale, targets & $\begin{array}{l}\text { Uses of relaxation training, lifestyle intervention and spirituality } \\
\text { training; reasons for integrating the } 3\end{array}$ \\
\hline 2 & $\begin{array}{l}\text { Description and } \\
\text { application of } \\
\text { intervention; sleeping }\end{array}$ & $\begin{array}{l}\text { Application and techniques; initiation of the 16MGTR relaxation } \\
\text { training; discussion of the changes in the problems of sleeping } \\
\text { time, practices and religious rituals before sleep; group workshop; } \\
\text { homework }\end{array}$ \\
\hline 3 & Relaxation; eating & $\begin{array}{l}\text { Review of homework; repetition of 16MGTR; discussion on eating } \\
\text { and drinking behaviours; discussion on prayer before eating; group } \\
\text { workshop; homework }\end{array}$ \\
\hline 4 & Relaxation; exercise & $\begin{array}{l}\text { Review of homework; initiation of 16MGTR; discussion on exercise } \\
\text { and practice of yoga in daily life and its religious impacts; group } \\
\text { workshop; homework }\end{array}$ \\
\hline 5 & Relaxation; awareness & $\begin{array}{l}\text { Review of homework; initiation of 7MGTR; discussion on } \\
\text { awareness in body relaxation during daily activities; hearing } \\
\text { cautiousness; remembering God; group workshop; homework }\end{array}$ \\
\hline 6 & $\begin{array}{l}\text { Relaxation; conflict } \\
\text { resolution }\end{array}$ & $\begin{array}{l}\text { Review of homework; repetition of 7MGTR; discussion on } \\
\text { awareness and resolving daily conflicts; religious meditation; } \\
\text { group workshop; homework }\end{array}$ \\
\hline 7 & $\begin{array}{l}\text { Relaxation; religion } \\
\text { orientation; conflict } \\
\text { resolution }\end{array}$ & $\begin{array}{l}\text { Review of homework; initiation of } 4 \text { MGTR, discussion on decision- } \\
\text { making; resolving daily conflicts and effects of religious orientation } \\
\text { on it; group workshop; homework }\end{array}$ \\
\hline 9 & $\begin{array}{l}\text { Relaxation; } \\
\text { communication }\end{array}$ & $\begin{array}{l}\text { Review of homework; repetition of } 4 \mathrm{MGTR} \text {, discussion on } \\
\text { empathic communication and expressing feelings; discussion on } \\
\text { creativity in lifestyle; group workshop; homework }\end{array}$ \\
\hline 10 & Relaxation; leisure time & $\begin{array}{l}\text { Review of homework; relaxation through recall; discussion on } \\
\text { leisure time and religious orientation }\end{array}$ \\
\hline 11 & $\begin{array}{l}\text { Relaxation; time } \\
\text { management }\end{array}$ & $\begin{array}{l}\text { Review of homework, relaxation through recall along with } \\
\text { counting; discussion on time management and importance of } \\
\text { prayer in time management and integration of self }\end{array}$ \\
\hline 12 & Integration & $\begin{array}{l}\text { Review of homework, relaxation by counting alone and with } \\
\text { religious imagery; review of the sessions; discussion on prevention } \\
\text { of relapse }\end{array}$ \\
\hline
\end{tabular}

MGTR = muscle group tension-relaxation

search has shown the effectiveness of PRT (which was one part of our IRT programme) on anxiety factors of personality except for emotional stability (factor C) [17], IRT expands the treatment options and we found that it was effective in increasing factor $\mathrm{C}$ as well. Other studies support these findings $[19,23,35]$.

Factor $\mathrm{C}$ is related to emotional stability and has a high correlation with other factors such as $\mathrm{H}, \mathrm{O}, \mathrm{Q} 3$, and Q4 [2]. The increase in the mean scores in factor $\mathrm{C}$ in our study group may be a consequence of IRT interventions on enhancing ego strength and feeling of security in the subjects. They, therefore, showed fewer signs of becoming upset or having unusual tenseness after the treatment; they had more self-control and faced life with a realistic approach. They also increased their ability to ignore

المجلة الصحية لشرق المتوسط، منظمة الصحة العالمية، المجلد الخامس عشر، العدد ب، 9 . ب 
Table 3 Comparison of means of personality factors in the study group and the control group

\begin{tabular}{lcc}
\hline Factor & $\begin{array}{c}\text { Mean difference } \\
\text { t-value }\end{array}$ & $\begin{array}{l}\boldsymbol{P} \text {-value } \\
\text { - } \text { - pre) }\end{array}$ \\
\hline C & -2.61 & 0.014 \\
G & 2.06 & 0.048 \\
H & -2.93 & 0.006 \\
O & 3.03 & 0.005 \\
Q4 & 3.22 & 0.003 \\
\hline
\end{tabular}

frustration and felt less tired. These findings are consistent with the interpretation for factor $\mathrm{C}$, suggesting all of above are components of $\mathrm{C}$ factor $[2,3]$. Altogether these variations indicate emotional stability as an indicator of psychological health. We saw the same results in the subjects' daily report and their homework during the treatment. Interestingly enough, this factor did not show a significant change after PRT interventions.

Factor $\mathrm{O}$ is the 2 nd factor that significantly changed in this study. The presence of a high score in factor $\mathrm{O}$ in a $16 \mathrm{PF}$ profile suggests psychological distress (anxiety/ depression). High score subjects needlessly worry, are depressed, feel worthless and inadequate, feel a vague sense of dread, have low self-esteem and are emotionally unstable. Significant decrease in our sub- jects' scores in the study group compared to the control group indicates that there had been some increase in self-esteem, self confidence, and self-sufficiency.

The similarity of variations in factors Q4, C and O in their tendency to reduce anxiety supports the objective of our study. The reduction of scores in factor Q4 for our study group indicates the transition of subjects from free-floating anxiety, being tense, restless and emotionally volatile and having a poorly controlled libido to relaxed, easygoing and "un-frustrated" people. Moreover, high scores in Q4 indicate negative correlation with self-control $[2,3]$. Self-control includes well-being, positive analysis and impression of self; any change in this factor affects the functions of the individual. Someone who cannot manage his/her psychological energy does not have stability in his/her emotions. Successful management of anxiety results in increasing emotional stability and improving quality of life and feeling healthy [36].

Another factor in $16 \mathrm{PF}$ that changed after treatment was factor $\mathrm{H}$. This factor correlates with anxiety factors of personality [2]: a low score in factor $\mathrm{H}$ indicates anxiety. Inhibition and shyness make individuals emotionally careful, sensitive to perceived threats and lacking in self-esteem. They seem to suffer silently

\begin{tabular}{|c|c|c|c|c|}
\hline \multirow[t]{2}{*}{ Factor } & \multicolumn{2}{|c|}{ Post-test score } & \multirow[t]{2}{*}{ t-value } & \multirow[t]{2}{*}{$P$-value } \\
\hline & Mean & $S D$ & & \\
\hline \multicolumn{5}{|l|}{ State anxiety } \\
\hline Study group & 31.87 & 8.53 & 4.00 & $<0.0001$ \\
\hline Control group & 52.32 & 10.57 & & \\
\hline \multicolumn{5}{|l|}{ Trait anxiety } \\
\hline Study group & 29.81 & 8.75 & 4.20 & $<0.0001$ \\
\hline Control group & 44.14 & 10.96 & & \\
\hline
\end{tabular}

$S D=$ standard deviation.

المجلة الصحية لشرق المتوسط، منظمة الصحة العالمية، المجلد الخنامس عشر، العدد ب، 9 . ب 
in their own self-imposed restrictions: the prototypical wallflowers [3]. Our findings with respect to factor $\mathrm{H}$ indicate that the participants could manage themselves in this area as well. They could communicate successfully and manage shyness and inhibition.

The change in factor $\mathrm{G}$ (expedient versus conscientious), although not a very large change in our study group, is not interpretable in the framework of our hypothesis. This change may indicate a kind of decrease in the forces of super-ego, since the increase in the scores of factor C (ego strength) may increase flexibility, social adaptation and rational decision-making [2], and this may support our findings too. This change may also be related to other variables such as the effect of instrumentation rather than the treatment applied.

\section{Study limitations}

This study suffers from some limitation with regard to the number and selection of participants and the nature of the interventions. The participants were selected from among individuals referred to the clinic, thus we cannot generalize the findings to others who did not volunteer to receive the intervention. Increase in emotional stability and reduction in anxiety may also have been influenced by factors other than the content of the intervention.

The study could have been extended in some ways to include other comparison groups with variations in the level of intervention. Using a larger sample and careful instrumentation would have increased the validity of the study.

\section{Conclusion}

Our findings indicate that integrative relaxation leads to emotional stability and reduction in anxiety. Emotional stability by itself results in success and happiness, 2 very important elements of a happy and healthy life. The changes observed in the state, and especially trait, of anxiety scores in the study group and the subjective feelings of the subjects provide more support for the effectiveness of our interventions.

\section{Practical implications}

The findings of this study can be applied to solve the difficulties that individuals with anxiety symptoms and emotional instability encounter in their daily lives. By paying more attention to the ability of patients to learn to self-manage their psychological problems through integrative relaxation, patient educators may be able to increase the effectiveness of their activities; at same time they can help their patients to be more independent in the treatment of their illnesses. Further research into the efficacy of programmes such as IRT is necessary from both the scientific and economic viewpoint.

\section{Acknowledgements}

We would like to thank Professor Dadsetan for her comments on the earlier versions of the study and Thalieh Counselling Centre in Tehran for financing this research.

\section{References}

1. Weiten W. Psychology: themes and variations, briefer version, 4th ed. Pacific Grove, California, Brooks/Cole, 2000:384.
2. Cattell HB. The16PF personality in depth. Champaign, Illinois, Institute for Personality and Ability Testing Inc., 1989. 
3. Craig RJ. Interpreting personality tests: a clinical manual for the MMPI-2, MCMI-III, CPI-R, and 16PF. New York, John Wiley \& Sons, 1999.

4. McCrae RR, Costa PT. The stability of personality: observations and evaluations. Current directions in psychological science, 1990, 3:173-5.

5. Davis M, Eshelman ER, McKay M. The relaxation \& stress reduction work book, 5th ed. Oakland, California, New Harbinger Publications, Inc., 2000.

6. Janbozorgi M, Noori N. [Anxiety and stress psychotherapy]. Tehran, SAMT, 2003 [in Farsi].

7. Dadsetan P, Janbozorgi M, Noori N. [The effectiveness of progressive relaxation training on child anxiety, academic performance and memory]. Journal of psychology (Tehran), 2001, 5(1):4-30 [in Farsi].

8. Schneider $\mathrm{RH}$ et al. A randomized controlled of trial of stress reduction for hypertension in older African Americans. Hypertension, 1995; 26(5):820-9.

9. Borkovec TD, Sides K. Critical procedural variables related to the physiological effects progressive relaxation: a review. Behavioral research and therapy, 1979, 17:119-26.

10. Borkovec TD, Costello E. Efficacy of applied relaxation and cognitive behavioral therapy in the treatment of generalized anxiety disorder. Journal of consulting and clinical psychology, 1993, 61(4):611-9.

11. Rasid M, Parish TS. The effects of two types of relaxation training on student levels of anxiety. Adolescence, 1998, 33(129):99-101.

12. Ost LG, Westling BE. Applied relaxation vs cognitive behavior therapy in the treatment of panic disorder. Behavior research and therapy, 1995, 33:145-58.
13. Clum GA, Surls R. A meta-analysis of treatments for panic disorder. Journal of consulting and clinical psychology, 1993, 61(2):317-26.

14. Lehrer PM, Woolfolk RL. Principles and practice of stress management, 2nd ed. New York, Guilford Press, 1993.

15. Heimberg RG. Cognitive and behavioral treatment for social phobia: a critical analysis. Clinical psychology review, 1989, 9:107-28.

16. Deffenbacher JL, Stark RS. Relaxation and cognitive relaxation treatments of general anger. Journal of counseling psychology, 1992, 39(2):158-67.

17. Janbozorgi M. [The study of the effect of progressive relaxation training on anxiety factor of personality] [MA thesis]. Tehran, Tarbiat Modares University Press, 1992 [in Farsi].

18. Cattell RB. The scientific analysis of personality. Baltimore, Penguin, 1965.

19. Janbozorgi M. [The effects of short-term group psychotherapy (multimodal approach) with and without religious orientation on anxiety and stress] [PhD thesis]. Tehran, Tarbiat Modares University, 2000 [in Farsi].

20. Latorre MA. A holistic view of psychotherapy: connecting mind, body and spirit. Perspectives in psychiatric care, 2000, 36(2):67-8.

21. Stephens R. Imagery: strategic intervention to empower clients. Clinical nurse specialist, 1993, 7:170-4.

22. Ost LG, Breitholtz E. Applied relaxation vs. cognitive therapy in the treatment of generalized anxiety disorder. Behavioral research and therapy, 2000, 38:777-90.

23. Kabat-Zinn $\mathrm{J}$ et al. Effectiveness of a meditation-based stress reduction program. American journal of psychiatry, 1992, 149:936-43. 
24. Carlson R, Shield B, eds. Healers on healing. Los Angeles, California, Jeremy $P$. Tarcher, 1989.

25. Diagnostic and statistical manual of disorders ((DSM-IV), text revision. Washington DC, American Psychiatric Association, 2000.

26. Dadsetan P, Delkhamosh MT. Standardization of 16PF questionnaire for Iranian Community, 4th ed. Tehran, Tehran University, Samt Ltd, 2008.

27. IPAT Staff. Administrators manual for the 16PF. Champaign, Illinois, Institute for Personality and Ability Testing, 1991 (http://WWW.16pfew.com, accessed 24 January 2005).

28. Spielberger CD, Gorsuch RL, Lushene RD. Manual for the State-Trait Anxiety Inventory (self-evaluation questionnaire). Palo Alto, California, Consulting Psychologists Press, 1970.

29. Spielberger CD. Manual for the StateTrait Anxiety Inventory (revised ed.). Palo Alto, California, Consulting Psychologists Press, 1983.
30. Spielberger CD. Assessment of state and trait anxiety: conceptual and methodological issues. The southern psychologist, 1985, 2:6-16.

31. Panahi SM. [Survey of validity and reliability of State-Trait Anxiety Inventory in Iran] [MA thesis]. Tehran, Tarbiat Modares University, 1991 [in Farsi].

32. Berenstein DA, Borkovec TD, HazlettStevens $\mathrm{H}$. New directions in progressive relaxation training. Westport, Praeger, 2000.

33. Palmer S, Dryden V. Counseling for stress. London, Sage, 1995.

34. Meichenbaum DH. Stress inoculation training. New York, Pergamon Press Inc., 1990.

35. Olson M, Sneed N. Anxiety and therapeutic touch. Issues in mental health nursing, 1995, 16:97-108.

36. Vaillant GE. Aging well. Boston, Little Brown, 2002. 